\title{
Ganhos sociais, inflexões na política econômica e restrição externa: novi- dades e continuidades no Governo Lula ${ }^{\dagger}$
}

\author{
Fernando Augusto Mansor de Mattos* \\ Frederico G. Jayme Jr.*
}

\begin{abstract}
RESUMO - O objetivo deste ensaio é discutir as principais diretrizes da política econômica durante o governo Lula, destacando em especial a mudança de orientação ocorrida a partir de 2006, avaliando-se, em seguida, os efeitos dessas mudanças de formulação de política econômica sobre o crescimento do PIB e também sobre indicadores selecionados de mercado de trabalho. Para contextualizar os resultados em termos de variação do PIB, será feita uma breve comparação histórica entre os mandatos presidenciais desde os anos 1950, de tal forma a situar claramente os resultados do mandato do governo Lula (bem como das mudanças de inflexão em sua política econômica) em perspectiva histórica. Parece não haver muitas dúvidas de que o governo Lula (2003-2010) obteve o melhor desempenho da história recente brasileira em termos de evolução do PIB per capita e inclusão social. Antes de Lula, apenas Itamar Franco, e seu bem sucedido programa de estabilização, havia terminado seu mandato com bons índices de aprovação, mas nem de longe semelhantes ao do governo Lula.
\end{abstract}

Palavras-chave: Crescimento. Emprego. Mercado de trabalho. Brasil.

\section{INTRODUÇÃO}

Parece não haver muitas dúvidas de que o governo Lula (2003-2010) obteve o melhor desempenho da história recente brasileira em termos de evolução do PIB per capita e inclusão social. Entre os governos dos curtos períodos democráticos após a Revolução de 1930 é certamente o melhor. Se os resultados do PIB per capita obviamente são inferiores àqueles produzidos pelo "milagre econômico" do início dos anos 1970, ou mesmo dos anos 1950, a desconcentração da renda do trabalho, inclusão social e mais democratização das ações de estado o colocam como um governo bem sucedido.

Não bastasse, a partir de uma exitosa política fiscal anticíclica e de um aumento do crédito nos bancos públicos, foi possível amortecer os efeitos da maior crise internacional desde A Grande Depressão de 1930. De fato, os índices de popularidade do presidente e de seu governo no final de 2010 demonstram inequivocamente este fato. Antes de Lula, apenas Itamar Franco,

\footnotetext{
†Gostaríamos de agradecer os comentários de Irineu de Carvalho Filho, isentando-o - obviamente - de equívocos remanescentes.

* Professor adjunto na Faculdade de Economia da Universidade Federal Fluminense e bolsista PNPD alocado na Assessoria Técnica da Presidência do IPEA. Endereço eletrônico: fermatt@uol.com.br.

${ }^{* *}$ Professor associado do Departamento de Economia e do Cedeplar da Universidade Federal de Minas Gerais e bolsista do CNPq. Endereço eletrônico: gonzaga@cedeplar.ufmg.br.
} 
e seu bem sucedido programa de estabilização, havia terminado seu mandato com bons índices de aprovação, mas nem de longe semelhantes ao do governo Lula.

Se há motivos para elogiar seus bons resultados no front social, há também dificuldades que não foram ultrapassadas e parecem estar longe de serem resolvidas. A maior delas, e mais problemática, pois exerce um efeito deletério de longo prazo sobre a capacidade de crescimento da economia brasileira, é a restrição externa. A incapacidade do governo em tomar medidas mais audaciosas para evitar a valorização do câmbio em relação ao dólar acima da média de outros países é a manifestação mais cabal de sua fragilidade. Uma taxa de câmbio valorizada, um aumento do déficit em conta corrente nos últimos três anos e as elevadas taxas de juros dificultam o manejo da política econômica. Tudo isso demonstra uma característica singular neste governo. Ao mesmo tempo em que promoveu, via políticas de transferência de renda e política fiscal anticíclica, ganhos sociais importantes, garantiu aos rentistas ganhos elevados via política monetária.

Vale dizer, em que pese a ojeriza de parte da elite ao ex-presidente Lula, provavelmente por um inconfessável preconceito por sua origem popular, foram exatamente os muito ricos os mais beneficiados com a política de juros altos e valorização do câmbio nos últimos anos. Este fato, ajudado pela demanda internacional por commodities primárias que garantiu rendas elevadas ao setor agroexportador, provavelmente possibilitou uma concentração da renda e da riqueza significativas. Infelizmente os dados disponíveis dão conta apenas da renda do trabalho e apenas estimativas muito aproximadas permitem confirmar a hipótese acima descrita, em relação à distribuição funcional da renda, sem contar que a estrutura tributária brasileira é bastante regressiva, ainda.

O objetivo deste ensaio é discutir as principais diretrizes da política econômica durante o governo Lula, destacando em especial a mudança de orientação ocorrida a partir de 2006, avaliando-se, em seguida, os efeitos dessas mudanças de formulação de política econômica sobre o crescimento do PIB e também sobre indicadores selecionados de mercado de trabalho. Para contextualizar os resultados em termos de variação do PIB, será feita uma breve comparação histórica entre os mandatos presidenciais desde os anos 1950, de tal forma a situar claramente os resultados do mandato do governo Lula (bem como das mudanças de inflexão em sua política econômica) em perspectiva histórica.

\section{POLÍTICA MACROECONÔMICA EM DOIS ATOS: LULA I E LULA II}

A política econômica do governo Lula pode ser dividida em duas partes, cada uma representando seus dois mandatos. O primeiro mandato se caracterizou pela continuidade do 
excessivo conservadorismo do período FHC, particularmente a manutenção de uma política fiscal que, embora lograsse êxito na redução da dívida líquida, mostrou-se mal sucedida em garantir um crescimento econômico maior do que a média da América Latina ou mesmo do resto do mundo (conforme a Tabela 1, o Brasil cresceu entre 2003-2006 4,0\% contra 3,8\% do resto do mundo). No caso da política monetária, a manutenção de taxas nominais de juros elevadas. Nada diferente, portanto, do tradicional remédio ortodoxo, naquele momento ancorado pelo argumento do mercado da necessidade de garantir a credibilidade de um governo de esquerda.

No segundo mandato, particularmente após a mudança no Ministério da Fazenda, ocorrida em março de 2006, assistimos a uma inflexão na política fiscal, sobretudo à utilização da sua característica anticíclica. De fato, do ponto de vista do controle dos gastos, excetuandose o período do imediato pós-crise (final de 2008 e todo o ano de 2009), o que ocorreu foi uma diminuição do arrocho fiscal, uma vez que os dados não corroboram a hipótese de relaxamento da política fiscal, levando em conta que os gastos primários se elevaram menos do que o PIB no período 2007-2008. Somente a partir de 2009 é que os gastos primários se elevam acima do PIB, obviamente decorrente da crise internacional em 2008 e estagnação em 2009. ${ }^{1}$ Neste caso o segundo governo Lula procedeu a uma política tipicamente Keynesiana, a de utilizar o gasto público e o crédito via bancos públicos para amortecer os impactos da crise. Ressalte-se que é uma estratégia oposta às tradicionais políticas de "cortar despesas para colocar a casa em ordem", bem ao gosto da ortodoxia pouco criativa.

O fato novo importante na política fiscal no segundo governo Lula é o PAC, que garantiu algum fôlego em setores que há tempos não eram objeto de preocupação do Estado: habitação popular e infraestrutura rodoviária. Com efeito, os resultados podem ser considerados alvissareiros, haja vista que o setor de construção civil cresce a taxas elevadas, ao passo que as obras de infraestrutura viária evitaram o cenário desolador dos anos Collor-FHC. Obviamente há muito a ser feito, e o papel do Estado é fundamental, particularmente no setor aeroportuário, e para consolidar o impulsionamento de alguns setores industriais específicos e que foram recuperados no governo Lula, depois de anos de letargia, como, por exemplo, o setor naval.

Com efeito, foram exatamente algumas características importantes da economia brasileira, combinadas com políticas bem articuladas, que permitiram combater os efeitos negativos da crise financeira internacional. Merecem destaque, conforme Coutinho (2010), o potencial do mercado interno; elevação dos investimentos em infraestrutura; um sistema bancário público que serviu como amortecedor da queda na liquidez com o agravamento da crise em 2009 e a solvência externa de curto prazo.

1 Todos os dados aqui citados se encontram em www.ipea.gov.br. 
A questão externa de curto prazo merece uma discussão, pois é certamente o ponto frágil da política econômica do governo Lula. De fato, o Brasil ainda não apresenta uma inserção internacional competitiva nos setores industriais de alta e média intensidade tecnológica, o que tem gerado um problema crônico de ajuste nas contas externas. Precisamente, os saldos em conta corrente dependem fundamentalmente do comportamento da demanda externa, de tal sorte que em períodos de forte demanda externa por produtos intensivos em recursos naturais e commodities primárias o país consegue manter um saldo comercial, mas com instabilidade do saldo em conta corrente. Ainda, a "maldição" dos recursos naturais acaba por impulsionar um padrão de especialização comercial gerador de instabilidades.

Não bastasse, a política monetária sanciona um processo de valorização cambial que, num mundo ofertante de liquidez para países emergentes, agrava os resultados em conta corrente e cria um círculo vicioso que acaba por sancionar ainda mais a especialização comercial em bens com baixo conteúdo tecnológico. De fato, uma maior inserção de produtos com maior intensidade tecnológica é o que pode vir a garantir a possibilidade de crescimento de longo prazo não constrangido pelo balanço de pagamentos. Vale dizer, na incapacidade de fazer o catching up, países como o Brasil - com um padrão de especialização no comércio exterior essencialmente voltado para commodities primárias, bens de baixa intensidade tecnológica e bens intensivos em recursos naturais e mão de obra - dependem, em última instância, de condições favoráveis na demanda externa para manter um crescimento sustentado livre de crises externas. Este parece ser o que ocorreu após 2003: o desempenho comercial favorável se deu em produtos com baixo dinamismo no mercado internacional e dependente da demanda externa para produtos de baixo conteúdo tecnológico. Pelo Gráfico 1 é possível observar que o padrão de especialização comercial brasileiro não se modificou substancialmente nos últimos 20 anos.

O Gráfico 1 demonstra que a evolução da participação das commodities primárias, assim como os produtos de alta e média intensidade tecnológica no total das exportações do Brasil não se alteraram significativamente de 1989 a 2009. Com exceção das commodities primárias, os demais produtos, embora tenham alcançado um pico em 2000, não ultrapassaram a faixa de participação de $25 \%$ em relação às exportações totais. A mudança no sinal da balança comercial e nas transações correntes no Brasil após 2001 não ocorreu a partir de uma diversificação da pauta de exportação, tampouco do aumento no conteúdo tecnológico de seus produtos exportados. Ao contrário, esse resultado está principalmente relacionado ao aumento da comercialização de commodities primárias no mercado mundial, revelando o não rompimento da restrição externa estrutural ao crescimento de longo prazo. A liberalização comercial dos anos 1990 não foi capaz de modificar seu padrão de especialização em produtos de baixo teor tecnológico. 
Vale dizer, a simples liberalização dos mercados não é capaz de substituir a presença do Estado como orientador de setores dinâmicos competitivamente. Neste caso, a restrição externa não é rompida e o crescimento de longo prazo livre de constrangimentos no balanço de pagamentos não se beneficia de investimentos em setores dinâmicos no comércio internacional. Não obstante o governo Lula tenha lançado o Programa de Desenvolvimento Produtivo (PDP) em 2008 com objetivos, entre outros, de aumentar o grau de intensidade tecnológica das exportações brasileiras e diminuir a vulnerabilidade externa, seus resultados ainda não são visíveis nos resultados das contas externas.

GRÁFICO 1 - EXPORTAÇÕES (FOB) POR INTENSIDADE TECNOLÓGICA: BRASIL 1989-2009

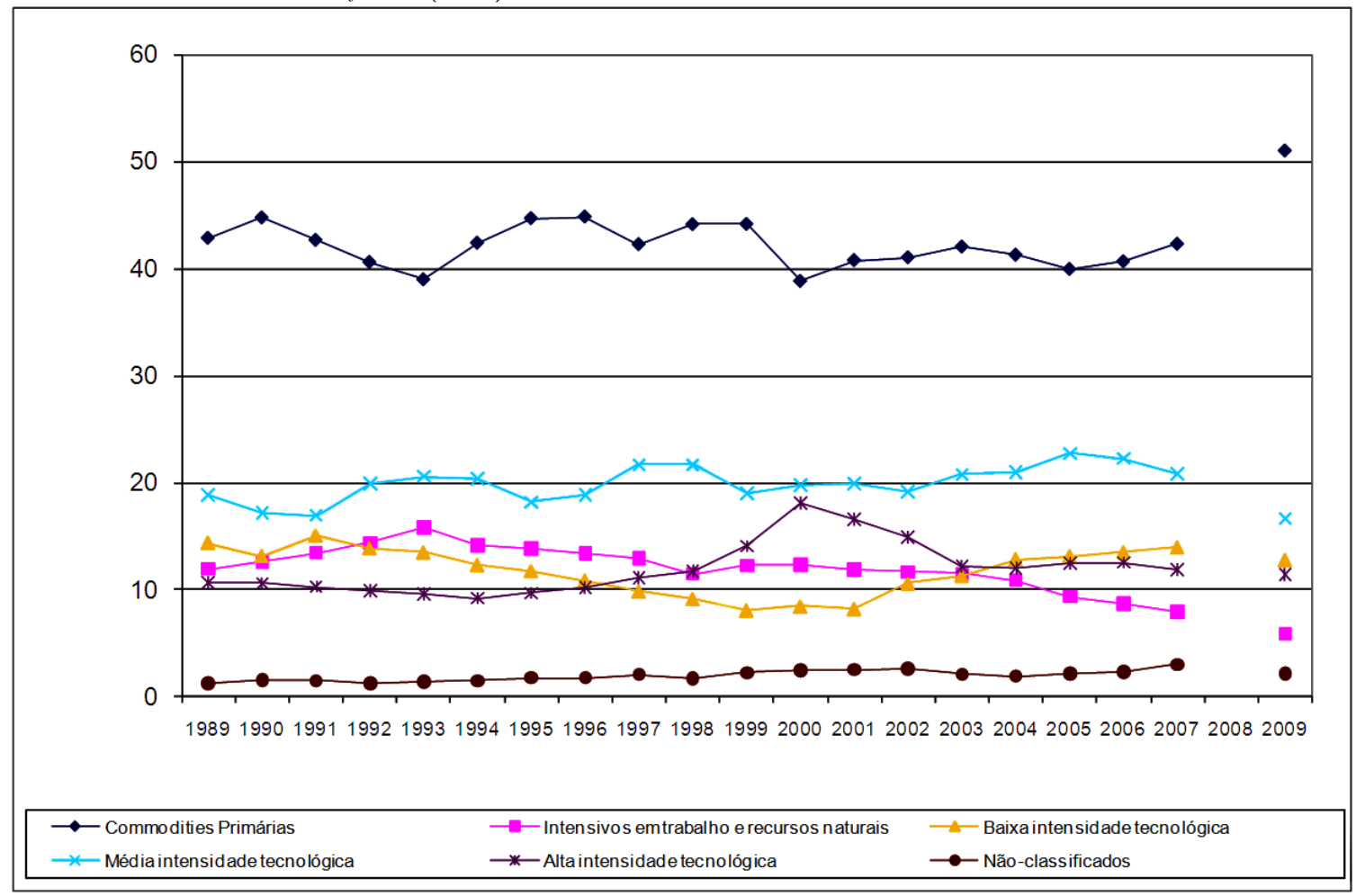

FONTE: UNCDB.

Obs: Há um problema nos dados em 2008 no sistema da UNCTAD.

\section{RESULTADOS SOCIAIS}

A Tabela 1 revela a variação média anual do PIB e do PIB per capita de cada mandato presidencial ${ }^{2}$, tomando-se os dados oficiais do IBGE, bem como os dados de variação do PIB mundial vis-à-vis da América Latina em cada período histórico.

2 Os dados aqui calculados referem-se a variações anuais para cada período assinalado, embora até a posse de Fernando Collor os presidentes iniciassem o seu mandato em 15 de março (sem contar que, dados os percalços da história política brasileira, muitos dos presidentes tomaram posse em datas diferentes das originalmente definidas como constitucionais). De todo modo, tomando-se os dados como apresentados na tabela é possível fazer uma avaliação histórico-comparativa de qualidade suficiente para propósitos deste ensaio. A partir de FHC, o início dos mandatos presidenciais coincidia com o calendário gregoriano. 
Uma primeira característica que salta aos olhos é que a economia brasileira, desde os anos 1950, teve como padrão um crescimento bem acima das médias mundial e da América Latina, exceto no breve período de governo do presidente Castelo Branco, em contexto de adoção de uma política econômica recessiva enquanto eram implementadas as reformas do PAEG, e no governo Figueiredo, durante o qual o crescimento da economia brasileira esteve apenas um pouco abaixo da média mundial e do continente latino-americano, que se encontrava então mergulhado em severa recessão por conta das restrições impostas pela crise da dívida externa.

Esse padrão de crescimento que permitia ao Brasil crescer acima das médias mundial e do continente em que se encontra foi claramente rompido nos anos 1990. A adoção (tardia, se comparada ao que ocorreu em diversos outros países da América Latina ${ }^{3}$ ) de políticas alinhadas com o chamado Consenso de Washington, a partir da posse do presidente Fernando Collor, inaugurou um período em que a economia brasileira passou a crescer abaixo da média mundial e da média de seu continente. Tal fato se mostra bastante explícito desde 1990 e revela uma pequena melhora no primeiro mandato de FHC, que inclui dois anos de modesta e efêmera recuperação econômica durante a vigência do Plano Real, mas não de magnitude suficiente para permitir que o crescimento do PIB brasileiro se encontrasse acima de 70\% da média mundial e apenas 79,5\% da média latino-americana no período 1995-1998 (primeiro mandato de FHC).

Durante o segundo mandato de FHC, o desempenho da economia brasileira, vis-à-vis a economia mundial, deteriorou-se ainda mais, atingindo um patamar equivalente a apenas $63,5 \%$ do crescimento do PIB mundial. Esse mesmo período coincidiu com a pior crise econômica da América Latina - então ainda mais grave do que a crise que havia acometido o continente no ano de 1980 - desde o pós-guerra e só por isso o desempenho relativo da economia brasileira situou-se acima da média do subcontinente. Deve-se destacar, porém, que, comparando-se com todos os outros mandatos presidenciais desde 1950, o segundo mandato de FHC teve o terceiro pior desempenho em termos de PIB per capita, sendo menos pior apenas do que o mandato do presidente Figueiredo ${ }^{4}$ (no auge da crise da dívida externa brasileira) e do breve período Collor, marcado por uma recessão impactante e uma crise institucional com os resultados já esperados e estudados em termos de expectativas geradas para os investimentos privados e também os do setor público. Em seu conjunto, o mandato de FHC de oito anos ostentou um crescimento do PIB per capita de apenas $0,8 \%$ ao ano, em média.

3 Ver Sader e Gentili (1996).

4 Deve-se ressalvar, porém, que, no período do mandato de FHC a economia mundial crescia muito mais $(3,4 \%$ ao ano, em média) do que no período de Figueiredo (2,7\% ao ano, em média). Também para efeito comparativo (e, neste caso, com um resultado um pouco mais condescendente para o período FHC), a economia da América Latina, durante os 8 anos de FHC, obteve um crescimento, em média, semelhante ao que havia tido nos 5 anos de João Figueiredo. 
Durante os oito anos do presidente Lula é possível constatar dois momentos bastante distintos em termos de crescimento do PIB, do PIB per capita, bem como na comparação internacional. O "espetáculo do crescimento" prometido no primeiro mandato ficou somente no discurso, conforme mostram os dados da Tabela 1. No período 2003-2006, a economia vinha exibindo, desde o início dos anos 1990 crescimento bem abaixo da média mundial, bem como aquém da média Latino-Americana. A despeito de ter exibido um crescimento acima do que ocorrera nos três mandatos presidenciais que o precederam (além do de Figueiredo), o desempenho da economia brasileira no primeiro mandato de Lula poderia ter sido muito melhor tendo em vista o cenário internacional então vigente ${ }^{5}$.

No segundo mandato de Lula, o crescimento médio anual do PIB superou em 1,1 ponto percentual o resultado do primeiro mandato e, se for levado em consideração o PIB per capita, superou em 1,3 ponto percentual (por ano) o resultado do primeiro mandato. Mas é na comparação internacional que os respectivos desempenhos se distinguem de forma mais clara: considerando-se a comparação com a média mundial, pode-se afirmar que o resultado do PIB brasileiro no segundo mandato foi duas vezes melhor do que o primeiro (75\% do PIB mundial, entre 2003 e 2006, contra 149\% do PIB mundial no período 2007-2010); da mesma forma, quando a comparação é feita com a média da América Latina, as diferenças são evidentes ( $76 \%$ contra $133 \%)$.

De fato, o papel das políticas anticíclicas, particularmente da política fiscal via aumento do gasto público principalmente após a crise internacional de 2007/2008, neste caso merecendo destaque o PAC (ainda que a taxa de investimento público no Brasil continue muito baixa), é de grande importância no segundo governo Lula. Ademais, a queda das taxas nominais e reais de juros (ainda que muito altas) e um aumento vigoroso do crédito público, neste caso ainda no primeiro governo Lula, são particularmente importante. Com efeito, a mudança na direção do Ministério da Fazenda em 2006 é o ponto diferenciador dessas políticas. ${ }^{6}$

O mandato de Lula também deve ser analisado em termos de PIB per capita comparando-se com os demais presidentes. A última vez que o PIB per capita havia crescido, em média anual, durante um mandato presidencial, acima do que ocorreu no segundo mandato de Lula, foi no período Geisel, quando a economia estava sofrendo forte desaceleração depois do chamado "milagre econômico" durando o governo Médici, mas, de todo modo, ainda crescia de

5 Tomando-se como referência períodos equivalentes aos respectivos mandatos dos presidentes brasileiros, a economia mundial exibiu, no período 2003-2006, o melhor desempenho (medido em termos de crescimento da produção e da renda) desde a derrocada do sistema de Bretton Woods, ocorrido entre 1971 e 1973 (Tabela 1). 6 Para os dados do crédito em geral e do crédito público, particularmente via Fundos Constitucionais, conferir Jayme Jr e Crocco (2010). 
maneira significativa, na esteira do último plano nacional de desenvolvimento adotado no Brasil, o II PND. No segundo mandato de Lula, o PIB per capita também ficou abaixo dos respectivos resultados dos mandatos de Médici, JK e Costa e Silva, quando se faziam sentir os primeiros efeitos do "milagre econômico" do governo militar, e superou todos os demais (Tabela 1).

Tomando-se o conjunto do período Lula (2003-2010), o PIB per capita cresceu cerca de 2,8\% ao ano, em média, valor que supera significativamente o PIB per capita obtido nos oito anos de FHC (crescimento de apenas $0,8 \%$ ao ano, em média), bem como o desempenho do PIB per capita do período Jânio-Jango, o de Castelo Branco e de todos os presidentes a partir de Figueiredo, inclusive (e com ênfase) o próprio. Não se pode negligenciar o fato de que o período Lula se beneficiou de uma conjuntura internacional favorável até a crise de 2008/09, particularmente uma maior liquidez internacional, a ascensão da China e os preços dos bens de consumo primários. Não obstante, o que aqui queremos ressaltar é exatamente a comparação do crescimento do PIB em cada governo vis-à-vis outras economias.

TABELA 1 - PIB E PIB PER CAPITA POR MANDATOS PRESIDENCIAIS E COMPARAÇÃO INTERNACIONAL - VARIAÇÃO MÉDIA ANUAL (EM PERCENTUAL) POR PERÍODO

\begin{tabular}{|c|c|c|c|c|c|c|}
\hline & PIB & $\begin{array}{c}\text { PIB } \\
\text { per capita }\end{array}$ & $\begin{array}{c}\text { PIB } \\
\text { Mundial } \\
\end{array}$ & \begin{tabular}{c|} 
PIB \\
Am Latina \\
\end{tabular} & $\begin{array}{c}\text { PIB sobre } \\
\text { PIB mundial }\end{array}$ & $\begin{array}{c}\text { PIB sobre } \\
\text { PIB Am Lat }\end{array}$ \\
\hline $\begin{array}{l}\text { GV - Café Filho } \\
(1951-1955)\end{array}$ & 6,7 & 3,6 & 5,1 & 5,0 & 131,8 & 133,4 \\
\hline $\begin{array}{l}\text { JK } \\
(1956-1960)\end{array}$ & 8,1 & 4,9 & 4,3 & 5,2 & 187,2 & 156,5 \\
\hline $\begin{array}{l}\text { Jânio-JG } \\
\text { (1961-1963) }\end{array}$ & 5,2 & 2,3 & 4,1 & 4,0 & 126,1 & 130,4 \\
\hline $\begin{array}{l}\text { Castelo } \\
(1964-1966)\end{array}$ & 4,2 & 1,2 & 6,0 & 5,6 & 69,6 & 74,2 \\
\hline $\begin{array}{l}\text { Costa e Silva } \\
(1967-1968)\end{array}$ & 7,0 & 4,0 & 4,6 & 5,2 & 151,5 & 132,7 \\
\hline $\begin{array}{l}\text { Médici } \\
(1969-1973)\end{array}$ & 11,4 & 8,5 & 5,2 & 6,8 & 217,9 & 168,8 \\
\hline $\begin{array}{l}\text { Geisel } \\
(1974-1978)\end{array}$ & 6,7 & 4,1 & 3,4 & 4,7 & 195,2 & 142,1 \\
\hline $\begin{array}{l}\text { Figueiredo } \\
(1979-1984)\end{array}$ & 2,4 & 0,2 & 2,7 & 2,4 & 89,4 & 99,4 \\
\hline $\begin{array}{l}\text { Sarney } \\
(1985-1989)\end{array}$ & 4,3 & 2,4 & 3,9 & 2,6 & 111,2 & 166,0 \\
\hline $\begin{array}{l}\text { Collor-Itamar } \\
(1990-1994)\end{array}$ & 1,3 & $-0,3$ & 2,6 & 3,3 & 50,5 & 40,2 \\
\hline $\begin{array}{l}\text { FHC I } \\
(1995-1998)\end{array}$ & 2,4 & 0,9 & 3,4 & 3,1 & 70,7 & 79,5 \\
\hline $\begin{array}{l}\text { FHC II } \\
(1999-2002)\end{array}$ & 2,1 & 0,6 & 3,4 & 1,4 & 63,5 & 148,8 \\
\hline $\begin{array}{l}\text { Lula I } \\
(2003-2006)\end{array}$ & 3,5 & 2,2 & 4,6 & 4,6 & 75,0 & 76,0 \\
\hline $\begin{array}{l}\text { Lula II } \\
(2007-2010)\end{array}$ & 4,6 & 3,5 & 3,1 & 3,4 & 149,2 & 133,7 \\
\hline
\end{tabular}

FONTE: IBGE e FMI.

NOTA: Elaboração própria. 
Um esforço interpretativo interessante também pode ser feito analisando-se a evolução recente do emprego formal, colocando-o sob recente perspectiva histórica.

A Tabela 2 revela a evolução dos saldos de emprego formal por setores de atividades na primeira década do século XXI. Os dados revelam que a geração de empregos formais começa a se acelerar em 2004 (após um resultado péssimo em 2003, comparável ao que vinha ocorrendo no triênio 2000-2002), sofrendo novamente uma inflexão positiva em 2007, com novo resultado expressivo em 2010. Certamente, neste último caso, repondo parte dos empregos que haviam sido perdidos em 2009, quando a crise internacional impactou nos investimentos da economia brasileira, refletindo-se no mercado de trabalho. Em termos líquidos, o período Lula criou cerca de 11,1 milhões de empregos formais em seus oito anos, o que significa cerca de 1,39 milhão em média anual. No primeiro mandato a geração líquida de postos de trabalho formais foi de 4,65 milhões contra 6,47 milhões no segundo mandato (40\% maior no segundo do que no primeiro mandato, a despeito da forte desaceleração do ano atípico de 2009). Para comparar, registre-se que, nos três últimos anos do mandato de FHC, a geração líquida de postos de trabalho foi de pouco mais de 2 milhões de empregos formais, o que equivale a uma média de apenas 670 mil por ano, valor equivalente a cerca de $40 \%$ do que foi criado por ano no último mandato de Lula.

TABELA 2 - SALDO DE EMPREGOS FORMAIS CRIADOS A CADA ANO, POR SETOR DE ATIVIDADE - BRASIL 2000-2010

\begin{tabular}{|c|c|c|c|c|c|c|c|c|c|c|c|}
\hline SETOR & 2000 & 2001 & 2002 & 2003 & 2004 & 2005 & 2006 & 2007 & 2008 & 2009 & 2010 \\
\hline Extrativa & 3709 & 2451 & 5583 & 6605 & 10337 & 9530 & 12052 & 9762 & 8671 & 2036 & 15345 \\
\hline $\begin{array}{l}\text { Mineral } \\
\text { Ind. de Trans- }\end{array}$ & & & & & & & & & & & \\
\hline formação & 192863 & 103822 & 161170 & 128701 & 504610 & 177548 & 250239 & 394584 & 178675 & 10865 & 647199 \\
\hline Serv.Util.Públ. & -15290 & 1540 & 5277 & 3147 & 4566 & 13533 & 7369 & 7752 & 7965 & 4984 & 16142 \\
\hline $\begin{array}{l}\text { Constução } \\
\text { Civil }\end{array}$ & -1627 & -33404 & -29425 & -48155 & 50763 & 85053 & 85796 & 176755 & 197868 & 177185 & 341627 \\
\hline Comércio & 175472 & 209805 & 283261 & 225908 & 403940 & 389815 & 336794 & 405091 & 382218 & 297157 & 373866 \\
\hline Serviços & 283928 & 310962 & 285797 & 260285 & 470123 & 569705 & 521609 & 587103 & 648259 & 500177 & 860275 \\
\hline Adm.Pública & 3182 & 11774 & 10204 & 9830 & -382 & 21599 & 8253 & 15252 & 10316 & 18075 & 27758 \\
\hline Agropecuária & 9795 & -17128 & 40579 & 58198 & 79274 & -12878 & 6574 & 21093 & 18232 & -15369 & 123998 \\
\hline Outros & 5564 & 1257 & -32 & 824 & 45 & 76 & 0 & 0 & 0 & 0 & 0 \\
\hline TOTAL & 657596 & 591079 & 762414 & 645433 & 1523276 & 1253981 & 1228686 & 1617392 & 1452204 & 995110 & 2406210 \\
\hline
\end{tabular}

FONTE: CAGED Min. Trabalho e Emprego.

NOTA: Elaboração própria.

Em termos setoriais, conforme explicita a Tabela 3 , as atividades de serviços, secundadas pelas atividades de comércio e a seguir pelas de indústria de transformação foram as que mais geraram postos de trabalho no conjunto do governo Lula. Merece destaque, porém, o fato de que, exceto no caso das atividades extrativistas, em todos os setores de atividades o segundo mandato de Lula gerou mais postos de trabalho do que no primeiro. A diferença mais signi- 
ficativa, em termos relativos, foi obtida nas atividades de construção civil, que haviam gerado cerca de apenas 43 mil postos de trabalho formal (média anual) entre 2003 e 2006, e passaram para mais de 223 mil (em média anual) no quadriênio seguinte (para registro, ressalte-se que, nestas atividades, houve uma redução líquida não desprezível de postos de trabalho no período 2000-2002).

Por fim, para complementar a análise desse desempenho em termos de geração líquida de postos de trabalho formal (ou seja, evolução do estoque de empregos formais a cada ano, sem levar em conta a variação percentual que cada acréscimo de estoque significava, a cada ano, no mercado de trabalho formal), deve-se avaliar qual o impacto desse movimento de geração de empregos sobre a taxa de desemprego.

TABELA 3 - GERAÇÃO MÉDIA DE EMPREGOS FORMAIS POR PERÍODO E POR SETOR DE ATIVIDADE - BRASIL

\begin{tabular}{lrrr}
\hline \multicolumn{1}{c|}{ SETOR } & 2000-2002 & 2003-2006 & 2007-2010 \\
\hline Extrativa Mineral & 3914 & 9631 & 8954 \\
Ind de Transformação & 152618 & 265297 & 307831 \\
Serv Util públ & -2824 & 7154 & 9211 \\
Construção Civil & -21485 & 43364 & 223359 \\
Comércio & 222846 & 339114 & 364583 \\
Serviços & 293562 & 455431 & 648954 \\
Adm Pública & 8387 & 9825 & 17850 \\
Agropecuária & 11082 & 32792 & 36989 \\
Outros & 2263 & 236 & 0 \\
TOTAL & 670363 & 1162844 & 1617729 \\
\hline
\end{tabular}

FONTE: CAGED Min.Trabalho e Emprego.

NOTA: Elaboração própria.

O Gráfico 2 apresenta a evolução da taxa de desemprego aberto na região metropolitana de São Paulo (RMSP) desde março de 1985, destacando seu comportamento para cada mandato presidencial desde que a pesquisa do DIEESE é feita. Destaca, também, a taxa média por mandato e a taxa média no período que vai desde janeiro de 1985 até dezembro de 2009. Por fim, são feitas duas estimativas para a taxa de desemprego aberto nos próximos 6 anos, uma delas supondo que o PIB crescerá 5,5\% ao ano, em média, entre 2010 e 2015, e outra supondo que crescerá 6,5\% ao ano, em média, no mesmo período. Assim, pode-se ter uma estimativa da taxa de desemprego no final do último ano do governo Lula e da taxa para os próximos cinco anos após Lula, quando serão completados 30 anos do início da redemocratização no Brasil. 

GRÁFICO 2 - TAXA DE DESEMPREGO ABERTO NA REGIÃO METROPOLITANA DE SÃO PAULO
ENTRE MARÇO DE 1985 E DEZEMBRO DE 2009

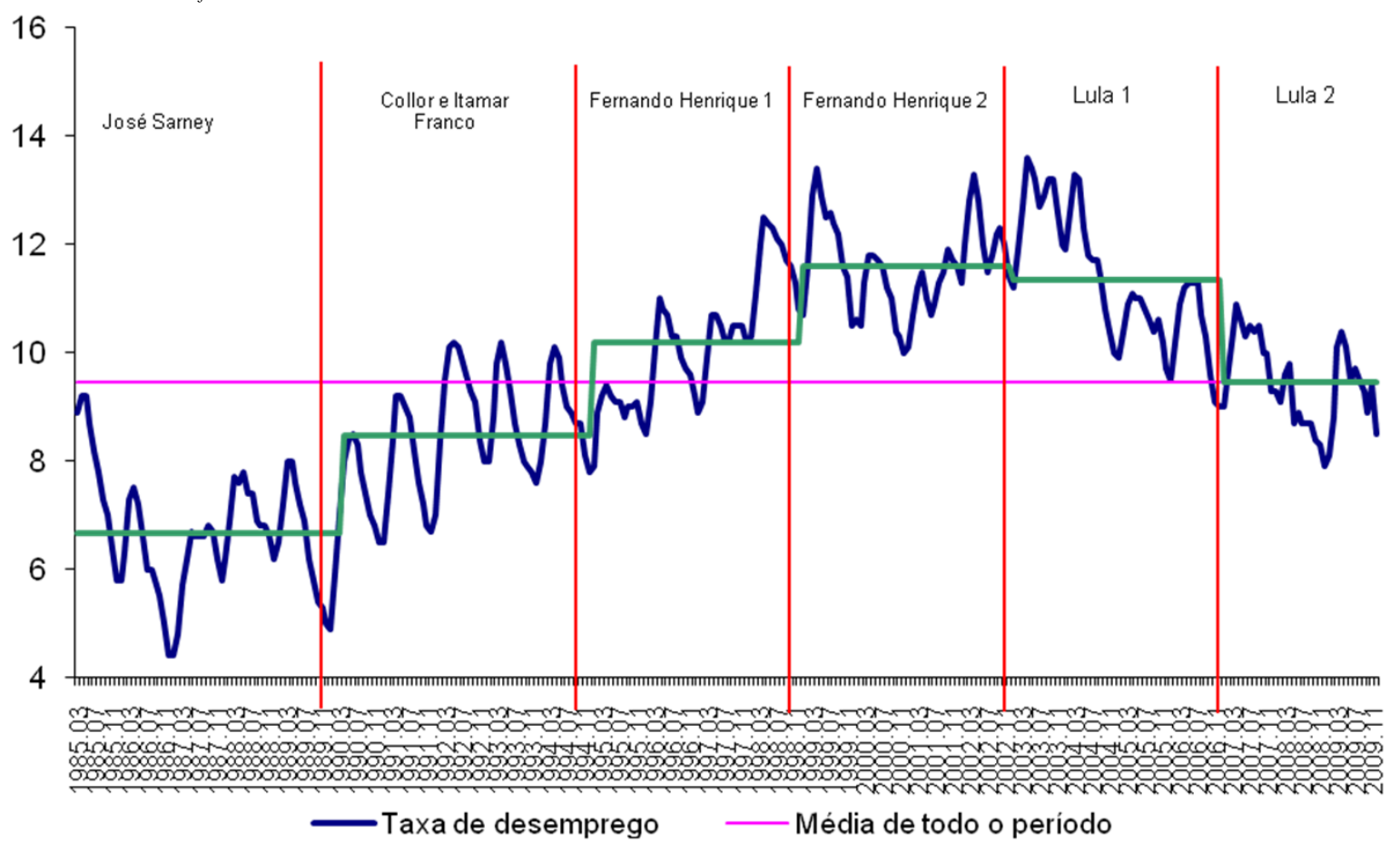

FONTE: Dieese.

NOTA: Elaboração IPEA.

Os dados revelam que foi no final dos anos 1980 que a taxa de desemprego teve o seu menor valor em todo o período analisado. Na média, o mandato de Sarney ostentou uma taxa de 6,6\% do desemprego aberto na $\mathrm{RMSP}^{7}$, atingindo um valor bastante reduzido no final do período, quando a economia brasileira, apesar da alta inflação de 1989, teve um crescimento não desprezível (3,2\%) do seu produto interno bruto.

O ano de 1990 marca uma robusta mudança no patamar da taxa de desemprego aber-

7 As duas principais taxas de desemprego medidas no país são a PME (Pesquisa Mensal do Emprego), pesquisada e calculada pelo IBGE nas seis principais regiões metropolitanas do Brasil (São Paulo, Rio de Janeiro, Belo Horizonte, Salvador, Recife e Fortaleza), e a PED (Pesquisa de Emprego e Desemprego), medida pelo DIEESE nas mesmas regiões metropolitanas mencionadas anteriormente, exceto na do Rio de Janeiro e inclusa a de Brasília, em convênios com diversas instituições estaduais. Aqui a taxa de desemprego avaliada será a da PED, pois no caso da PME houve uma mudança metodológica em 2002 que impede uma comparação dos dados posteriores a essa mudança com aqueles que a precederam. Tomando-se as taxas de desemprego calculadas pelas PEDs de todas as regiões metropolitanas pesquisadas pelo DIEESE, optou-se por avaliar a taxa de desemprego da região metropolitana de São Paulo, por se tratar daquela que concentra um maior peso de emprego industrial que as demais e também por não ter sofrido descontinuidade desde sua implementação, no início da década de 1980. Entre as modalidades de taxa de desemprego medidas, optou-se por tomar a taxa de desemprego aberto, pois ela se assemelha mais do que a taxa de desemprego total à taxa de desemprego aberto da PME. Além disso, deve-se registrar que a forma mais habitual de se medir e divulgar a taxa de desemprego é a sua modalidade de desemprego aberto, tanto no Brasil quanto na literatura internacional. Dessa forma, será deixada de lado uma análise das taxas de desemprego oculto pelo desalento e também oculto pelo trabalho precário na região metropolitana de SP, apesar da riqueza analítica permitida pelas mesmas. Para ver as diferenças metodológicas entre as taxas e as definições de desemprego, verificar nos respectivos sítios de internet do DIEESE e da Pesquisa Mensal de Emprego (PME, do IBGE). 
to, que atingiu a média anual de $8,5 \%$ no período Collor/Itamar.

A recuperação econômica ocorrida logo após a partida do Plano Real ${ }^{8}$, além de efêmera, teve uma característica que não havia sido verificada após a recessão anteriormente ocorrida (no início dos anos 1980) na economia brasileira. A recuperação do biênio 1994-1995, ao contrário do que ocorrera em 1985-1986 ${ }^{9}$, não logrou recuperar, especialmente nas atividades industriais - as que dão maior dinamismo ao conjunto da atividade econômica -, os postos de trabalho que haviam sido eliminados na recessão do início da década ${ }^{10}$ de 1990. Tal resultado deveu-se ao fato de que a valorização cambial, a abertura comercial desacompanhada de uma política industrial, bem como a inserção externa subordinada e passiva a que a estrutura industrial brasileira foi submetida pela política econômica adotada desde o início dos anos 1990 promoveram uma descontinuidade das principais cadeias produtivas da indústria brasileira, revelada pela ampliação das importações de bens intermediários, com efeitos evidentes sobre a criação de emprego e de valor agregado na atividade industrial (BALTAR, 1996). Ademais, a crise fiscal do Estado - aprofundada pelos crescentes gastos com pagamentos de juros da dívida interna - e também a concepção liberal de política econômica impediram a ampliação de gastos públicos e a adoção de políticas sociais que pudessem atenuar a crise do emprego ${ }^{11}$ e, mais ainda, definir um novo padrão de acumulação produtiva.

O primeiro mandato de FHC consolidou e aprofundou a desregulamentação do mercado financeiro que havia sido iniciada por Collor, o que, no contexto de uma política econômica assentada no binômio juros altos - câmbio valorizado, aprofundou as dificuldades das empresas - especialmente as do setor industrial - com relação às suas possibilidades de enfrentamento da concorrência internacional, impulsionando novas rodadas de reestruturação produtiva e de negócios envolvendo fusões e aquisições, com efeitos significativos sobre o nível de emprego, tanto na indústria como nas atividades do setor terciário. ${ }^{12}$ No segundo mandato, a taxa de desemprego deu novo salto (média de 11,6\%), superando a média (já elevada) de pouco mais de $10 \%$ estabelecida no primeiro mandato.

No primeiro ano do primeiro mandato de Lula (Lula I, no Gráfico 3), o crescimento

8 No ano de implementação do Plano Real (1994) o PIB cresceu 5,3\% e, no ano seguinte, 4,4\%, desacelerando-se em 1996 , quando cresceu apenas $2,2 \%$.

9 Quando a economia brasileira teve uma variação do PIB real de, respectivamente, 7,8\% (em 1985) e 7,5\% (em 1986).

10 Cf. Baltar (1996).

11 A assunção, no debate econômico brasileiro, do termo "inempregáveis", por parte dos formuladores de política econômica do período, revela o grau de conformismo que o tema adquiriu no auge da hegemonia ideológica do neoliberalismo.

12 Destaca-se, neste aspecto, que os governos Lula I e Lula II não se livraram deste binômio. Como já ressaltaram Resende e Amado (2007), há um ciclo reflexo em que os países em desenvolvimento recorrem sistematicamente à poupança externa quando há disponibilidade de recursos externos, o que agrava o problema da valorização cambial ao mesmo tempo em que amplia o passivo externo. 
do PIB ainda foi decepcionante, até que a partir de 2004 e, principalmente, de 2006, conforme já acima descrito, uma nova postura da política econômica permitiu que a economia brasileira tirasse melhor proveito da conjuntura internacional em expansão, com efeitos imediatos sobre o nível de emprego. A taxa de desemprego aberto na RMSP declinou já a partir da segunda metade do primeiro mandato de Lula, de tal forma que no final do Lula I a mesma já havia atingido um patamar equivalente ao valor médio do período entre 1985-2009, embora a taxa média do primeiro mandato tenha fechado apenas um pouco abaixo da taxa média do segundo mandato de FHC. Nos segundo mandato de Lula, a taxa de desemprego continuou a cair, o que revela o dinamismo do mercado de trabalho, bafejado pelos bons ventos colhidos pela mudança na política econômica e pela continuada melhoria do cenário internacional ${ }^{13}$.

\section{CONCLUSÃO}

A perspectiva para os próximos anos, mesmo com uma queda na taxa de crescimento médio do PIB, é de redução expressiva da taxa de desemprego nas regiões metropolitanas (onde há estatísticas organizadas), mas também nas pequenas e médias cidades brasileiras. $\mathrm{O}$ desafio é avaliar os efeitos que o câmbio valorizado pode representar para a competitividade das exportações industriais, bem como seus efeitos sobre o balanço de pagamentos, uma vez que haverá mais pressão sobre o resultado em conta corrente, ainda mais se as projeções otimistas de um crescimento do PIB de 5,0\% se verificar no futuro próximo. Por mais que a economia brasileira e suas políticas de investimentos públicos e de incentivos aos investimentos privados possam promover ganhos de produtividade em decorrência de investimentos em infraestrutura, o desafio provocado pelo câmbio pode prejudicar a competitividade externa dos produtos industriais brasileiros, abortando a continuidade do próprio crescimento. Este é, combinado com a diminuição da concentração da renda e riqueza no país, provavelmente um dos principais desafios para os futuros governos.

13 Embora a taxas menores do que no período 2003-2006, a economia internacional manteve um razoável crescimento médio anual entre 2007 e 2010, especialmente por causa de seu desempenho antes da deflagração da crise do sub-prime do mercado imobiliário americano, ocorrida em setembro de 2008. De todo modo, a ascensão dos preços das commodities, nos anos mais recentes, favoreceu as atividades exportadoras brasileiras e a expansão da economia brasileira. 


\section{REFERÊNCIAS}

BALTAR, P.E.A. Estagnação da economia, abertura e crise do emprego urbano no Brasil. Ecconomia e Sociedade, n.6, jun.1996.

COUTINHO, L. A construção de fundamentos para o crescimento sustentável da economia brasileira. In: ALÉM, A. C.; GIAMBIAGI, F. O BNDES em um Brasil em transição. Rio de Janeiro: BNDES, 2010.

FILGUEIRAS, L. A. M. História do Plano Real. 3.ed. São Paulo: Boitempo, 2006.

JAYME JR., F.G.; CROCCO, M.A. Bancos públicos e desenvolvimento. Rio de Janeiro: IPEA, 2010.

PAULA, J. A. de (org.). Adeus ao desenvolvimento: a opção do governo Lula. 1.ed. Belo Horizonte: Autêntica, 2005.

RESENDE, M. F.; AMADO, A. M. Liquidez internacional e ciclo reflexo: algumas observações para a América Latina. Revista de Economia Política, v. 27, n.1. jan. 2007.

SADER, E.; GENTILI, P. (1996) (org.). Pós-neoliberalismo: as políticas sociais e o Estado Democrático. 3.ed. São Paulo: Paz e Terra, 1996. 